\title{
O mundo como sacramento: A a sacramentologia de Paul Tillich como crítica a um mundo em desintegração
}

\author{
Victor Siqueira Santos*
}

\begin{abstract}
RESUMO
O teólogo e filósofo teuto-americano Paul Tillich (1886-1965) é muito conhecido por sua capacidade de correlacionar as situações políticas, sociais e culturais que o cercavam e as respostas da tradição cristã. Este artigo visa expor brevemente as bases da sacramentologia tillichiana, que realçam fatores que contribuem para um suporte teórico da crítica do autor ao mundo moderno. Para Tillich, o elemento sacramental é imprescindível ao cristianismo. A sacramentologia constitui um elemento integrador que sempre aponta para o sentido último da natureza e da história. Partindo desse pressuposto, Tillich lançou um olhar crítico ao mundo moderno tal como vinha sendo construído pela sociedade burguesa, observando um mundo em desintegração ao qual o elemento sacramental se tornou importante componente crítico-construtivo.
\end{abstract}

Palavras-chave: Paul Tillich; teologia da cultura; sacramentologia; substância católica; princípio protestante

\section{THE WORLD AS SACRAMENT: PAUL TILLICH'S SACRAMENTO- LOGY AS A CRITICISM OF A DISINTEGRATING WORLD}

\begin{abstract}
The German-American philosopher and theologian Paul Tillich (18861965 ) is well known because of his capacity to correlate cultural, political, and social situations with answers given by the Christian tradition. This paper briefly exposes the grounds of Tillichian sacramentology which
\end{abstract}

\footnotetext{
* Graduado em teologia (Faculdade Batista do Rio de Janeiro - Seminário Teológico Batista do Sul do Brasil). Doutor em teologia sistemático-pastoral pela PUC-Rio.

Acesso ao Lattes: http://lattes.cnpq.br/7051636480812647
} 
underline factors that contribute to a theoretical support of the author's criticism of the modern world. In Tillich's thought the sacramental element is indispensable to Christianity. Sacramentology constitutes an integrating factor that always points to the ultimate meaning of nature and history. Upon this presupposition, Tillich highlighted a critical view on the way the modern world was being constructed by the bourgeoisie society, and what he saw as a disintegrating world, of which the sacramental element became an important critical-constructive component.

Keywords: Paul Tillich; theology of culture; sacramentology; catholic substance; protestant principle

\section{Introdução}

A visão de mundo de Tillich, pressuposta em toda a sua teologia da cultura, é fundamentada por uma sacramentalidade. Uso a categoria "mundo", aqui, não como um conceito estritamente técnico, mas com a intenção de expressar uma malha cultural formada por variados elementos (natureza, política, sociedade, história). Algumas vezes, ao longo da sua carreira, Tillich fez leituras de conjuntura, através das quais podemos perceber seus variados olhares sobre diversos âmbitos culturais. Nessas análises, também estão presentes, implícita ou explicitamente, suas profundas elaborações teóricas. Sua visão sobre o sacramento é uma delas. A visão sacramental tillichiana torna possível uma compreensão mais profunda das críticas que Tillich direciona à sociedade burguesa moderna, dominada pela técnica, pela física-matemática e pela economia autossuficiente. Mais do que críticas direcionadas à classe burguesa ou à ciência tecnológica, Tillich faz fundamentalmente, uma crítica a certa forma que estas têm de enxergar o mundo. Por isso, o presente artigo é dividido em três pontos: a relação entre sacramento e natureza; a relação entre sacramento e história; a crítica a um mundo em desintegração.

\section{A natureza}

Em 1952, Tillich escreve uma de suas pequenas autobiografias com o título "Autobiographical reflections" (Reflexões autobiográficas), como capítulo de um livro dedicado ao seu pensamento. Nele, o autor faz interessantes apontamentos sobre sua infância e como esta determinou sua forma de enxergar o mundo, em geral, e a natureza e a história, em particular. Tillich nasceu em uma pequena vila de nome 
eslavo, Starzeddel, num território, hoje, pertencente à Polônia. Aos quatro anos, se muda para Schönfliess, uma cidade com três mil habitantes ao leste de Brandenburg.

A cidade tinha caráter medieval. Era cercada por um muro, construída em torno de uma antiga igreja de estilo gótico, era acessada através de portões com torres sobre eles, administrada por uma prefeitura de estilo medieval, e dava a impressão de um pequeno mundo protegido e independente (TILLICH, in: KEGLEY; BRETALL [org.], 1964, p. 4)1.

Tillich ficou na cidade até os catorze anos de idade. Sendo que, entre os doze e os catorze, se revezava entre Schönfliess e Königsberg, uma cidade um pouco maior, mas com os mesmos traços medievais. Ele afirma que este período deve ter contribuído para o caráter romântico de seu pensamento, sobretudo em relação à sua visão sobre a natureza. Essa visão "é expressa predominantemente por uma atitude estético-meditativa em relação à natureza, distinguindo-se de uma relação científico-analítica ou técnico-controladora" (TILLICH, in: KEGLEY; BRETALL [org.], 1964, p. 4). Isso fez com que Tillich divergisse teologicamente tanto da visão de Albert Ritschl, que enxergava uma separação entre a natureza e a pessoa, quanto da visão calvinista ou puritana, que caminha na direção de um controle moral e técnico da natureza.

Tillich indica três causas formativas de sua relação com a natureza. Em primeiro lugar, uma relação mística advinda de sua infância. Em segundo, o contato com a poesia alemã e seu misticismo da natureza (Goethe; Hölderlin; Novalis; Nietzsche; Rilke). Em terceiro, a teologia luterana, que, diferente do calvinismo, afirma que o finito é capaz do infinito. Enquanto o calvinismo afirma, por exemplo, que, em Cristo, a natureza humana e divina permanecem separadas, o luteranismo afirmará que essas naturezas habitam em Cristo mutuamente.

Essa diferença significa que em terreno luterano a visão da presença do infinito em tudo que é finito era teologicamente afirmada, que um misticismo da natureza era possível e real, enquanto que, em terreno calvinista, tal atitude é suspeita de panteísmo e a transcendência divina é entendida

Todas as citações de obras em língua estrangeira são de tradução nossa. Termos-chaves aparecerão no original entre parêntesis e em itálico. 
de uma forma tal que, para um luterano, é suspeita de deísmo (TILLICH, in: KEGLEY; BRETALL [org.], 1964, p. 5).

O tom místico de Tillich em relação à natureza também pode ser visto em seus textos acerca dos sacramentos. Num texto, ainda do período alemão, de título "Natur und Sakrament" (Natureza e sacramento), Tillich apresenta uma proposta sacramentológica. É um tema delicado, visto que as controvérsias em torno dos sacramentos foram quesito fundamental na Reforma Luterana. Mas, mesmo assim, o autor busca revitalizar a importância do elemento sacramental para as igrejas protestantes. Para ele, o "desaparecimento (Verschwinden) completo do elemento sacramental (o mesmo não se pode dizer de cada sacramento individualmente) levaria ao desaparecimento do culto e à cassação (Aufhebung) da própria igreja” (TILLICH, in: HUMMEL [org.], 1992, p. 153$)^{2}$. Isto é, o interesse de Tillich não é primariamente debater sacramentos em particular, mas propor uma visão sacramental sem a qual, para ele, não há igreja. Mais tarde, em sua Teologia Sistemática, ele falará em "sentido amplo" e "sentido estreito" do sacramental, afirmando que a preocupação das igrejas com o sentido estreito e a quantidade de sacramentos eclesiais a fez esquecer o sentido sacramental mais amplo e profundo (TILLICH, 2014, p. 576).

A proposta sacramentológica tillichiana parte de uma interpretação da natureza. $\mathrm{O}$ autor apresenta alguns tipos de interpretação, as quais julga inadequadas, para, por fim, expor a sua própria.

A primeira interpretação da natureza trazida por ele é a "mágico-sacramental" (magisch-sakramentale). Essa é a visão da natureza dos povos primitivos na qual tudo que existe é dotado de uma energia capaz de tornar sacra qualquer coisa, e, portanto, ela é anterior a qualquer divisão entre sagrado e profano. "O poder natural (Wesensmacht) das coisas é o mesmo que seu poder sagrado, e o relacionar-se com elas é

2 Usaremos aqui a versão de 1930, ampliada a partir do texto de uma conferência dada em um evento organizado por um dos movimentos de renovação litúrgica da igreja luterana na Alemanha, em 1928. Este último pode ser encontrado em TILLICH, P. Natur und Sakrament. In: ALBRECHT, R (hg.). Gesammelte Werke. Band VII. Stuttgart, Evangelisches Verlagswerk, 1962, pp. 105-123. Há também uma tradução para o português que pode ser encontrada em TILLICH, P. Natureza e sacramento, in: A era protestante. São Bernardo do Campo: Ciência da Religião, pp. 121-137. 
sempre, ao mesmo tempo, técnico e ritualístico". (TILLICH, in: HUMMEL [org.], 1992, p. 159).

A segunda interpretação da natureza é a racional-objetiva (rational-gegenständliche), que pode ser vista paradigmaticamente na dominação moderna da natureza. $\mathrm{Na}$ interpretação racional-objetiva da natureza, o elemento mágico dá lugar ao controle técnico e à física matemática. Somente nessa interpretação, todas as coisas da natureza são vistas como objeto, no sentido estrito do termo. Essa foi a visão que tomou conta do mundo moderno, contra a qual Tillich se colocará por muitas vezes.

A terceira interpretação apresentada é a visão "biológico-vital" (biologisch-vitale), que é representada por uma filosofia do vital (Philosophie des Vitalen), na qual a natureza também é tomada de poder, mas um poder sem uma forma (Mächtigkeit ohne Form), um impulso sem significado (Schwung ohne Sinn) e, assim, é um romantismo do caos (Romantik des Chaos).

A quarta interpretação negada por Tillich é uma tentativa de volta à interpretação mágico-sacramental que ele chama de "ocultismo" (Okkultismus). Nela, se abre um novo olhar sobre os poderes da natureza que são ocultos à física e à biologia. E tais poderes dotam a natureza de um poder transcendental inato e oculto.

A quinta e última interpretação da natureza julgada por Tillich é a "simbólico-romântica" que também quer retomar a profundidade e o sentido da natureza, mas, diferente do ocultismo, ela o faz através da afirmação de um significado simbólico da natureza que é encontrado como "parábola do espírito" (Gleichnis des Geistes). Ou seja, há uma espécie de código espiritual na natureza que só o espírito é capaz de decifrar. No lugar do pansacramentalismo, entra um pansimbolismo (Pansymbolismus). Essa interpretação é rica fonte para uma visão sacramental, mas é inadequada, porque não supera os conhecimentos da física em torno da natureza (TILLICH, in: HUMMEL [org.], 1992, pp. 158-161).

Para Tillich, somente uma interpretação realista da natureza (realistischen Naturauffassung) é adequada para fundamentar uma sacramentologia. A interpretação realista é a tentativa de considerar seriamente os avanços da ciência moderna, e, através deles, apontar a possibilidade de um sentido mais profundo da natureza. Baseado em elementos da 
filosofia da natureza de Schelling e da mística da natureza em Goethe, Tillich afirma que a objetividade das coisas são simultaneamente seu poder (Das Sachliche der Dinge ist zugleich ihre Macht). Contudo, esse poder não está na forma empírica dos objetos, oculto em objetos especiais, ou mesmo analogamente contido no espírito subjetivo, mas, sim, em um nível de profundidade que ultrapassa tanto a objetividade quanto a subjetividade. Tillich diz:

O poder material é acessível somente em tal nível (Schicht) do ser que se situa antes da cisão entre qualidade objetiva (Gegenständlichkeit) e qualidade espiritual (Geistigkeit), no ser incindido (ungespaltenen) e pré-objetivo (vorgegenständlichen). Contudo, este ser não deve ser interpretado à maneira de uma interpretação vital da natureza, ou seja, uma dinâmica sem forma, antes, ele deve ser compreendido como uma substância possuidora de sentido (sinnhafter Gehalt), como potencialidade (Mächtigkeit) que é ao mesmo tempo materialidade. Se tivermos a possibilidade de olhar para a potencialidade material das coisas da natureza (sachgetragene Mächtigkeit der Naturdinge), teríamos então também a possibilidade de entender seu significado como elemento sacramental. Contudo, essa possibilidade permanece em princípio. Ela torna-se realidade na medida em que conseguimos alcançar a profundidade de nosso próprio ser incindido e pré-objetivo (ungespaltenen, vorgegenständlichen Sein). (TILLICH, in: HUMMEL [org.], 1992, p. 162)

A filosofia da natureza que pressupõe a sacramentologia tillichiana não está de acordo nem com a soberania e independência dos objetos encontrados na natureza, nem com a soberania da subjetividade do espírito. Há, sim, no nível da objetividade, uma potencialidade que também é sentido. Contudo, nem ela mesma e nem mesmo o espírito humano, em sua subjetividade, podem trazer à tona a dimensão mais profunda de sentido. Para o autor, há um nível no ser que supera a objetividade e a subjetividade, e somente nele podemos alcançar o verdadeiro sentido potencializado na natureza. Esse é o primeiro passo para a possibilidade da natureza como sacramento.

\section{A história}

Um segundo passo é necessário para uma visão cristã da natureza como sacramento: afirmar a relação da natureza com a história. A visão de Tillich sobre a história também traz consigo a experiência do 
período de sua infância e adolescência. $\mathrm{O}$ ambiente das cidades nas quais viveu foi responsável por um tom romântico em sua visão sobre a história. "Crescer em cidades nas quais cada pedra é testemunha de um período de centenas de anos atrás produz um sentimento de história, não como forma de conhecimento, mas como uma realidade viva na qual o passado participa no presente" (TILLICH, in: KEGLEY; BRETALL [org.], 1964, p. 5). Essa relação já é apontada por Tillich em sua reflexão autobiográfica. Tillich diz que sentiu a diferença entre essa relação com a história e a que encontrou nos Estados Unidos para onde saiu exilado. Lá, os jovens falavam sobre a história num tom intelectual e sem relação existencial. Enquanto na Europa a história está sempre ligada existencialmente a um passado, nos Estados Unidos, uma conexão com o passado foi perdida e, por isso, guia-se sempre em relação a um futuro. Por isso, a visão tillichiana de história ganhou tons de um romantismo influenciado por certa saudade da idade média, que não é um desejo de retornar a ela, mas um reconhecimento de que todas as coisas, em partes desse período histórico, participavam de uma harmonia histórica, bem como estavam sempre abertas ao infinito. Todo esse pano de fundo certamente foi influência-chave para a elaboração de seu conceito de teonomia.

Tillich também trata de natureza e história no texto "Natureza e sacramento". Para ele, a relação entre ambas é imprescindível para o cristianismo, pois, somente partindo do pressuposto dessa relação, é possível para o cristão construir uma relação entre a natureza e a história da salvação apresentada nos Evangelhos, bem como afirmar os sacramentos como portadores de uma potencialidade transcendente que também participa desta história. Então, Tillich primeiro afirma:

A natureza não é somente um círculo que retorna em si mesmo, como os gregos e os clássicos achavam. Ela também o é, mas ela é, além disso, uma linha. Há, nela, não somente eventos que se repetem, mas também história, que é única e conclusivamente direcionada. Há uma história do átomo e dos astros, há um devir macro e microcósmico que não tem a forma de um círculo, mas que a pressiona para frente. (TILLICH, in: HUMMEL [org.], 1992, p. 162). 
Tal linearidade só teria sentido, para Tillich, se estivesse em relação com uma história que fosse um lugar da vivência de sentido (Sinnerleben) e cumprimento de sentido (Sinnerfüllen) da humanidade. A história possui um rumo, e, esse rumo, no cristianismo, é entendido no contexto da história da salvação, da qual toda a natureza participa. Sendo assim, a história e o processo natural se tornam uma unidade. Ao passo que o processo natural participa do processo histórico, este, por sua vez, também é achado na natureza. A natureza, assim, é vista como possível lugar de manifestação do transcendente, que se dá na história. Ao relacionar a natureza à história da salvação, o cristianismo possibilita a "superação" do carácter sempre ambíguo da natureza.

Sobre o fundamento de tal compreensão histórico-realista da natureza, o elemento natural não é somente em si e para si, mas também, em sua conexão com o processo natural, que se dá na história, pode se tornar portador de uma potencialidade transcendente. A objeção contra o realismo sacramental de que ele faz da inabalável potencialidade ambígua da natureza uma portadora de potencialidade transcendental é superada: Através da relação com a história da salvação seriam também os elementos naturais des-demonizados (entdämonisiert). Nem seu poder seria perdido, nem seriam rebaixados ao nível da objetividade impotente, como muitas teologias reivindicam de mãos dadas com o empoderamento técnico-físico. Mas sim, através da interpretação realista da natureza, a potencialidade desses elementos naturais seria reconhecida. Através de sua inclusão na história da salvação, contudo, a ambiguidade e o demônico de sua potencialidade seriam tomados (genommen). (TILLICH, in: HUMMEL [org.], 1992, p. 163).

As palavras de Tillich acima, se descoladas do contexto de seu pensamento, podem nos levar à errada conclusão de que a realidade, no contexto da história da salvação, tem sua condição fundamental de ambiguidade transformada. Essa leitura cairia numa interpretação mágico-sacramental da natureza. Numa versão anterior desse texto, a partir de uma palestra em 1928, Tillich deixa claro que, na interpretação realista da natureza, "a crítica protestante contra qualquer uso, de caráter imediato, mágico ou mitológico da natureza como portadora da salvação é mantida." (TILLICH, in: ALBRECHT [hg.], 1962, p. 113). Portanto, a "des-demonização" da natureza quando integrada na história da salvação não pode ser interpretada como perda total de seu caráter 
demônico, mas como uma superação fragmentária de sua ambiguidade para que se torne transparência da salvação. Em linguagem tillichiana, na história da salvação, todas as coisas rumam para o "Novo Ser em Cristo", alvo que simboliza a superação total de todas as ambiguidades. Mas, quando este Novo Ser se manifesta na história, o faz sempre fragmentariamente, como revelação e ocultação. Nesse evento, a natureza tem "sua qualidade demônica superada no Novo Ser em Cristo" (TILLICH, in: ALBRECHT [hg.], 1962, p. 113), porém não ainda de forma plena. Ela é sim portadora (Träger), mas também é objeto (Gegenstand) da salvação e, portanto, não é sua operadora imediata. Para Tillich, somente a partir dessa interpretação da natureza é possível falar de uma visão sacramental adequada da mesma.

Obviamente, essa visão sacramental tillichiana entra em conflito com a visão católica. E, de fato, Tillich critica esta última em vários momentos. Ele diz claramente: "O pensamento sacramental protestante não pode voltar a um sacramentalismo mágico, como o ensino católico manteve até hoje. No campo protestante, não deve haver recaída a uma atitude pré-profética e pré-protestante" (TILLICH, in: ALBRECHT [hg.], 1962, p. 120). E, para Tillich, protestante que era, não era possível que nenhum objeto pudesse ter poder sem si mesmo sem que fosse necessário o elemento da fé para que este objeto se tornasse, de fato, sacramento. Ele diz: "Não há objeto sacramental, prescindido da fé, que a capture, porque ele é capturado por ela. Prescindida a correlação 'fé = sacramento', não há sacramento" (TILLICH, in: HUMMEL [org.], 1992, p. 169). Ou seja, a participação da consciência, de um "eu centrado", não pode ser descartada no ato sacramental.

Por outro lado, é curiosa a reivindicação que Tillich vem fazendo desde a década de 30, de que todas as igrejas possuem uma dimensão de catolicidade. No texto "Eine Betrachtung über Sinn und Grenzen evangelischer Katholizität" (Uma consideração sobre o sentido e os limites de uma catolicidade evangélica), ele diz:

Catolicidade significa validade para todos, isto é, no duplo sentido de uma reivindicação em todos e de uma pertinência para todos. A Igreja Católica representa com seu nome a reivindicação do cristianismo de se aplicar a todos e convir a todos. Ora, se essa ligação é insolúvel no 
cristianismo, não pode haver igreja cristã que não seja, na ideia, católica. (TILLICH, in: ALBRECHT [hg.], 1972, p. 92).

É necessário deixar claro que esta reivindicação não é um chamado à importação das estruturas das Igrejas Católicas pelas outras igrejas, mas é o apontamento feito por Tillich de que o protestantismo não deveria se esquecer desse elemento que deve estar sempre presente em todas as igrejas cristãs. Comentando sobre isso, Mueller diz:

A catolicidade é uma das marcas da igreja. Segundo Tillich, também o protestantismo a sustenta. Só que, ao contrário da catolicidade católica, fundada sobre a instituição Igreja e sobre o princípio da unidade na submissão à mesma, a catolicidade protestante "está totalmente ligada ao conteúdo da sua pregação, e nunca à sua forma de existência.". (MUELLER, 2006, p. 12).

Com o passar do tempo, a crítica tillichiana à visão sacramental da igreja católica continuou fundamentalmente a mesma, mas, no período americano, ela é feita de forma mais amena e num tom mais colaborativo. Higuet diz: "Com a sua mudança para os EUA, Tillich passou a se interessar mais pelas relações ecumênicas com a igreja católica e a perceber melhor a complementaridade entre as duas tradições" (HIGUET, 2008, p. 141). Essa mudança pode ser vista no texto "The permanent significance of the Catholic Church for Protestantism" (O significado permanente da igreja católica para o protestantismo), de $1941^{3}$.

Numa linguagem filosófico-religiosa, Tillich afirma que o sagrado pode ser experienciado pelo ser humano como "santidade do ser" ou como "santidade do que deveria ser". Nenhum dos dois tipos de experiência pode ser eliminado das formas religiosas sem graves consequências. Contudo, uma religião pode enfatizar uma ou outra. Se a ênfase recai sobre a santidade do ser, temos uma religião sacramental, já se se é dada maior ênfase à santidade do que deveria ser, temos uma religião escatológica. A primeira tem como representante o sacerdote, a segunda o profeta. A igreja católica, com seu sistema sacramental

3 Cf. TILLICH, P. The permanent significance of the Catholic Church for Protestantism. In: HUMMEL, G. (org.) Main works/Hauptwerke. Volume 6/Band 6. Berlin: De Gruyter; New York: Evangelisches Verlagswerk GmbH, 1992, pp. 236-242. 
representa uma religião sacramental, o protestantismo, com a constante denúncia contra as formas religiosas dadas, representa a religião profética. Contudo, ambas têm problemas se eliminam totalmente, em si, o elemento representado na outra. Nesse período, a crítica à concepção sacramental católica continua a mesma:

A igreja estabeleceu ela mesma com a incorporação da presença do sagrado, este que é dado, primeiramente em Cristo, através dele, na igreja e através da igreja naqueles que recebem as graças sacramentais distribuídas pela hierarquia. O sacerdote que administra o sagrado tem poder sacramental, especialmente na missa quando ele transforma os elementos seculares em realidade sagrada. (TILLICH, in: HUMMEL [org.], 1992, p. 236).

Já em relação ao protestantismo, Tillich afirma que este é, em si mesmo, o protesto contra qualquer forma de objetificação do sagrado, como também contra qualquer autoridade que sirva de mediadora entre a pessoa e o divino. Todos são leigos e chamados ao sacerdócio e, além de a autonomia de todas as esferas da ciência ser afirmada. Mas, Tillich também traz críticas ao protestantismo. Enquanto as igrejas protestantes se destacaram pelo protesto contra a estrutura sacerdotal e sacramental da Igreja Católica, esta, por sua vez, tem o poder de uma sólida existência frente a um protestantismo que secularizou seu veio profético e escatológico.

O Protestantismo precisa do permanente corretivo do Catolicismo e do influxo contínuo de seus elementos sacramentais para viver. O catolicismo, por sua própria existência, lembra ao protestantismo do fundamento sacramental sem o qual a atitude profético-escatológica não tem base, substância e poder criativo. O catolicismo representa a verdade de que o "sagrado do ser" (holy of being) precede o "sagrado do que deveria ser" (holy of what ought to be), que sem a "mãe", a Igreja sacerdotal-sacramental, o pai, o movimento profético-escatológico, não tem raízes. Este se torna ativismo cultural e utopismo moral. Este cessa de ser profético e se torna político, educacional ou científico. Este perde seu caráter religioso e se torna movimento secular, carregado por grupos seculares. (TILLICH, in: HUMMEL [org.], 1992, p. 238)

Aqui, Tillich já está apontando para o caráter vazio e secular da sociedade moderna, com o qual o protestantismo esteve, desde sempre, relacionado, quando não tomando suas rédeas mesmas. Por isso, era 
necessário que as igrejas protestantes resgatassem seu caráter sacramental. Nessa tarefa, a presença das Igrejas Católicas tem um importante papel, que é cumprido na Igreja Primitiva e Medieval mais do que na Igreja Católica moderna e da Contra-reforma, e no catolicismo grego mais do que no romano, tendo papel importante também o anglo-catolicismo. Contudo, mais uma vez, Tillich relembra que o Catolicismo é significante para o protestantismo por manter vivo a ideia de uma igreja sacramental, mas isso não significa que o protestantismo deveria assimilar, por isso, as práticas e o modo de pensar católicos. Ele diz:

É claro que isso não pode significar que o protestantismo precisa aceitar a distorção e demonização católico-romana da ideia sacramental da igreja: a identificação de uma igreja organizada com a presença do divino na história e a consequente reivindicação desta igreja por absoluticidade. $\mathrm{O}$ protestantismo iria desistir de si mesmo, de sua atitude profética e de seu caráter escatológico, se aceitasse tal reivindicação. (TILLICH, in: HUMMEL [org.], 1992, p. 239)

O Catolicismo, com a sua presença, expõe o problema com o qual o Protestantismo tem de lidar. Ele torna claro o esvaziamento escatológico que enfraquece a presença e a relevância de qualquer igreja cristã. Ao tratar desse perigo em sua Teologia Sistemática, Tillich afirma que toda igreja cristã deve conter em si o "princípio protestante" e a "substância católica". O emprego das palavras "católica" e "protestante" aqui não quer apontar para as igrejas que levam esses nomes. $\mathrm{O}$ "princípio protestante" e a "substância católica" estão para além de qualquer igreja concreta. "Ainda que se recubram em parte com seus correspondentes eclesiais, 'católico' e 'protestante' não se referem simplesmente a duas tradições eclesiásticas. Ambos são conceitos funcionais que se aplicam a certas configurações de conteúdos" (MUELLER, 2006, p. 8). Ou seja, são qualidades necessárias a qualquer forma de cristianismo.

O "princípio protestante", do qual Tillich já vinha tratando desde a década de 20 , é a força profética da igreja. É a vigia permanente para que nenhuma forma cultural ou elemento natural tome o lugar divino e o ato de denúncia, caso isso ocorra. Contudo, cabe indicar o esforço tillichiano de que o princípio protestante não é feito somente da negatividade da denúncia, mas também tem seu caráter positivo, e, 
portanto, formativo. O protesto não busca somente destruir uma forma, mas também propõe novas formas. E assim só pode fazer, porque está fundamentado numa "Gestalt", um poder positivo criador que o impulsiona. Portanto, o protestantismo é movido por uma tensão dialética que envolve protesto (quebra das formas) e Gestalt (criação de novas formas). "Esta tensão dialética não pode jamais ser perdida de vista. Dela, resulta o que em sua discussão com Barth Tillich chamou de 'paradoxo positivo'. Em relação ao protestantismo isto significa: correlacionar adequadamente o protesto e a Gestalt” (MUELLER, 2006, p.11). Esta última "é chamada por Tillich de 'Gestalt da graça', o que quer dizer a estrutura sagrada ou divina da realidade" (MUELLER, 2006, p. 11). A Gestalt da graça pode surgir como manifestação divina em toda e qualquer forma, sem se deixar captar por nenhuma delas, mesmo que seja uma igreja. ${ }^{4}$

A "substância católica" é a preservação da dimensão divina potencializada na realidade. É a sempre presente afirmação da possibilidade do divino ser simbolizado nos objetos, nos gestos e nas formas culturais. Para o cristianismo, as formas culturais são autônomas, mas podem e devem sempre estar abertas para sua dimensão religiosa. Ao passo que a captura do divino por formas religiosas deve ser denunciada, também é necessário olhar para a realidade moderna que soberanizou sua dimensão autônoma e se empenhar em uma busca de recuperação de sua dimensão sacramental. Tillich diz: “A fórmula 'princípio protestante e substância católica' se refere fundamentalmente ao sacramento como meio da Presença Espiritual" (TILLICH, 2014, p. 577). Isto é, o sacramento, é a universalização da presença do Espírito de Deus na realidade através da possível mediação simbólica de todas as coisas. Lembrar-se da substância católica do cristianismo é lembrar-se disso.

No já mencionado texto "The permanent significance of the $\mathrm{Ca}$ tholic Church for Protestantism, Tillich afirma a importância de as

4 Para uma coleção de textos em torno da dialética protestante, ver: ALBRECHT, R (hg.). Gesammelte Werke. Band VII. Stuttgart, Evangelisches Verlagswerk, 1962. Sobre o caráter formativo do protestantismo, ver: TILLICH, P. O poder formativo do protestantismo. In: A era protestante, pp. 223-237. Cf. também: de ABREU, F. H. A Gestalt da graça e os desdobramentos de uma consciência protestante no Brasil: responsabilidade social, ética e humanismo teológico. Juiz de Fora, 2015. 304 p. Tese. Pós-Graduação em Ciências da Religião, Universidade Federal de Juiz de Fora. 
igrejas protestantes reavivarem sua catolicidade, ou seja, seu caráter sacramental, simbólico. Ele diz: "O permanente significado da Igreja Católica para o Protestantismo é a sua poderosa representação do elemento sacerdotal e sacramental.” (TILLICH, in: HUMMEL [org.], 1992, p. 236). E ainda mais a frente:

O catolicismo, pela sua mera existência, lembra ao protestantismo do fundamento sacramental sem o qual a atitude profético-escatológica não tem bases, substância e poder criativo. Catolicismo representa a verdade de que o 'sagrado do ser' (Holy of being) tem que preceder o 'sagrado do que deveria ser' (The holy of what ought to be), que sem a 'mãe', a igreja sacerdotal-sacramental, o 'pai', o movimento profético-escatológico, não tem raízes. Este se torna ativismo cultural e utopianismo moral. Este deixa de ser profético e se torna político ou educacional ou científico. Ele perde seu caráter religioso e se torna um movimento secular, conduzido por grupos seculares (TILLICH, in: HUMMEL [org.], 1992, p. 238).

Tillich chama a atenção para a importância da atuação do elemento sacramental da igreja se desdobrando na história, exatamente porque, o autor descreve o período no qual escreve (1941), como um tempo marcado pela desintegração das massas e de ausências de símbolos de união (uniting symbols).

\section{O mundo em desintegração}

A teologia sacramental tillichiana está implícita em suas críticas ao mundo moderno. Nas leituras tillichiana da conjuntura de sua época, o que caracteriza o mundo moderno é exatamente a perda de um poder integrador. Uma dessas leituras pode ser encontrada no texto "Our disintegrating world" (Nosso mundo em desintegração), de 1941. Tillich diz que a palavra "mundo", "como uma unidade de grupos políticos interdependentes, abarcando toda a raça humana, nunca existiu antes." (TILLICH, in: PALMER [dir.], 1990, p. 158). Essa palavra ganha este significado a partir da Primeira Guerra Mundial. Na Segunda Guerra, o discurso oficial já era de que um mundo, que representava os melhores valores ocidentais, estava lutando a favor da reintegração de um mundo que estava sendo desintegrado por forças totalitárias. Na opinião de Tillich, essa afirmação é insuficiente. Para ele, a desintegração do mundo não se reduzia aos efeitos do totalitarismo (fascismo ou na- 
zismo), mas ia além. As raízes da desintegração do mundo estão nos valores e direções para onde a sociedade burguesa estava direcionando o mundo moderno. Portanto, as sociedades representadas pelas forças que estavam combatendo o totalitarismo (os aliados) também tinham parte no processo de desintegração do mundo. O discurso que torna a insurgência dos totalitarismos pelo mundo um mero acidente deve ser deixado de lado. Essas insurgências são efeitos de tal desintegração. Mas, para achar suas causas e entender os eventos históricos correntes, é necessário ir mais fundo. Tillich diz:

Integração é o ato no qual princípios contrastantes são unidos em um princípio maior e abrangente. Desintegração é o evento no qual tal princípio maior e mais abrangente perde sua força de união e os elementos contrastantes unidos nele se partem. O princípio integrador da sociedade que chegou a um fim em nosso período é a ideia e a realidade da harmonia entre natureza e razão na criação de uma natureza dominada pelo homem e uma sociedade dominada pela razão. Este princípio era a união e a força integradora durante o período de uma burguesia em construção, capaz de superar os contrastes econômicos, políticos, intelectuais e religiosos na vida e mente burguesa. Mas, ele perdeu sua força quando o crescimento da vida burguesa parou e começou a entrar em declínio. Nesse momento, que é em grande parte idêntico ao período pré-Primeira Guerra Mundial a desintegração do nosso mundo começou. (TILLICH, in: PALMER [dir.], 1990, pp. 157-158)

A desintegração, portanto, para Tillich se encontra na forma como a sociedade burguesa vem construindo o mundo moderno, forma esta evidenciada, sobretudo, no campo da economia. A expansão econômica baseada no mercado mundial e num imensamente rápido desenvolvimento tecnológico são os principais causadores de um cenário de desemprego que causa efeitos psicológicos e sociais, sobretudo sobre uma população que busca cada vez mais por segurança e estabilidade e acabam por confiarem seus anseios a um sistema de centralização do poder econômico e de um capitalismo dominador do Estado. Esse cenário é a causa, não de uma sociedade dividida em classes (como havia apontado Marx), mas de uma divisão interna que se encontra em todas as classes.

Ao serem submetidas às crises econômicas provocadas pelo sistema burguês, as classes são internamente divididas. Tendências fascistas 
invadem a alta burguesia. Apoios a grupos totalitários surgem entre uma classe média que vê seu padrão de vida ameaçado, bem como entre as desesperadas massas desempregadas que se tornam "produto de um mundo em desintegração, lutando contra e trabalhando a favor da desintegração, ao mesmo tempo" (TILLICH, in: PALMER [dir.], 1990, p. 159).

Juntamente com uma divisão nas classes, ocorre também uma divisão nas ideologias, fazendo com que não seja fácil fazer uma leitura "preto no branco" da situação. Liberais e socialistas possuem algumas bases em comum, enquanto movimentos nacionalistas usam de ideias vindas do movimento dos trabalhadores, já o nacionalismo religioso usa e abusa das ideias do socialismo religioso. A partir do confuso cenário ideológico surge uma divisão entre o racional e o irracional e, com isso, a irrupção de movimentos políticos e religiosos marcados por um anti-intelectualismo e um antirracionalismo.

Isso criou um tipo de autodesprezo dos fundamentos da racionalidade, um desacreditar no poder espiritual, uma inimizade autodestrutiva contra o pensamento e consequentemente um sentimento de falta de sentido, de inutilidade de qualquer luta por princípios, uma falta de desejo por lutar e morrer por um ideal. (TILLICH, in: PALMER [dir.], 1990, p. 162).

Para além dos desdobramentos políticos mencionados por Tillich acima, o direcionamento socioeconômico da sociedade burguesa acarreta inúmeras outras situações. O autor também aponta, ainda no período alemão, para a incidência dessa mentalidade desintegradora sobre a relação do ser humano com o mundo (tanto natural quanto técnico-cultural). Em seu texto de 1926, "A situação religiosa do tempo presente", Tillich é contundente em afirmar que o ser humano perdeu a relação comunitária que tinha com as coisas materiais à sua volta. E, sendo assim, elas se tornaram meramente coisas. Ele diz:

No livre-mercado o relacionamento com as coisas se tornou sem eros (eroslos), sem caráter comunitário (gemeinschaftslos), uma relação senhoril. As coisas se tornaram mercadoria, isto é, objetos cujo sentido é produzir lucro através da compra e venda e não ampliar o círculo das vidas pessoais. Elas são adquiridas e alienadas por meio de relação senhoril (herrschaftlich) e não por meio de uma relação comunitária ( $g e$ meinschaftsmäßig). (TILLICH, in: SCHARLEMANN [dir.], 1988, p. 54). 
E, mais a frente, em uma análise comparativa, Tillich aponta para a forma como as pessoas se relacionavam com os objetos na era pré-burguesa e como essa relação mudou na era pós-burguesa. Em suas palavras, percebe-se claramente a influência de sua visão de mundo adquirida na época de sua infância. Ele diz:

No passado, o relacionamento com as coisas era consagrado (geweiht) através da veneração (Ehrfurcht), santo e profundo respeito (heilige Scheu), através da piedade (Pietät) e da gratidão (Dank) diante da propriedade. $\mathrm{O}$ relacionamento com as coisas nos tempos pré-burgueses tinha em si algo de transcendente. A coisa, a propriedade, era símbolo de participação na realidade dada por Deus, e era qualificada (abgestuft) de acordo com a maior ou menor extensão na participação (Anteil) nela. Em contrapartida, a mercadoria é símbolo da finitude infinita (unendlichen Endlichkeit) da pura vontade de domínio (Herrschaftswillen). Consequentemente, as propriedades limitadas como a lavoura, a casa, o gado, a mobília, a roupa etc. perdem seu caráter de força simbólica. Elas se tornam mercadoria útil (Gerauchsware), determinada exclusivamente por uma finalidade de consumo, fabricada, tratada e distribuída sem eros ou caráter de individualidade (individualtitätslos). Elas recebem não somente uma ideia de sentido, mas também uma real estrutura (realen Gestalt) de ser-mercadoria (TILLICH, in: SCHARLEMANN [dir.], 1988, p. 54).

Esse é o coração da crítica de Tillich à maneira como as relações entre objetos e pessoas mudaram na sociedade burguesa. Os objetos, ao tornarem-se mercadoria, perdem uma relação de sentido real que tinham com os seus proprietários. Eles, enquanto símbolos da realidade dada por Deus, remetiam a um sentido do qual participavam. Como mercadoria, os objetos são resumidos a "meras coisas". Não possuem relação profunda alguma com quem as possui, a relação se restringe à mera posse e descarte.

Como tudo para Tillich é ambíguo, ele não deixa de dizer que essa relação de domínio sobre as mercadorias tem, religiosamente, também seu lado positivo: ela evita uma idolatria do objeto. Ou seja, o perigo de dar a este um caráter absoluto. Com isso, a pessoa está sempre acima dos objetos. Esse seria o efeito protestante da economia liberal. Por outro lado, esse tipo de economia "prende a pessoa a um serviço infinito, em um esvaziado reino das coisas e, através desse reino, torna a pessoa, em si, vazia e sacrificada ao finito. Este é o efeito do espírito 
burguês da economia liberal" (TILLICH, in: SCHARLEMANN [dir.], 1988 , p. 54). O caráter infinito do mundo dos objetos não é o da infinitude ligada ao eterno, mas de uma infinitude ligada à promessa de bens infinitos, ou seria melhor dizer, ilimitados. Para Tillich, essa qualidade que poderíamos chamar de "falso infinito" está por trás da insaciedade para o consumo que marca a sociedade moderna. Ele diz:

A perda do Eros da relação com as coisas corresponde à necessidade infinita pelas coisas e à possibilidade dada ao comerciante de despertar necessidades infinitas. O Eros e a piedade se direcionam para um círculo limitado de consumo, cujo conteúdo substancial (Gehalt) e forma simbolicamente forte (symbolkräftige Form) realizam (erfüllt) o espírito. As coisas, cujo conteúdo substancial fora perdido não satisfazem (befriedigen) e, assim, o espírito vaga de uma coisa a outra sem possibilidade de realização (Erfüllungsmöglichkeit). A pessoa esvaziada se encontra sem direcionamento do Eros. Ela está acessível a todo estímulo que lhe ocorre de fora. Sobre essa situação repousa a possibilidade do estímulo ilimitado da necessidade através da publicidade e da propaganda (TILLICH, in: SCHARLEMANN [dir.], 1988, pp. 54-55).

Mesmo nessa falha promessa de realização do espírito, Tillich indica que existe algo de positivo. $\mathrm{O}$ fato do ser humano ser estimulado por diversos meios que propõem uma satisfação espiritual que está para além da materialidade do produto, mostra que ele é alguém capaz de superar uma vida apática presa a meras determinações e necessidades biológicas. Isso o separa da pura animalidade e o faz um ser cultural. Por outro lado, seu aspecto negativo "significa a coação à atividade infinita, autossuficientemente intensa, esgotadora de todas as forças vitais, a serviço da necessidade ilimitada." (TILLICH, in: SCHARLEMANN [dir.], 1988, p. 55).

A busca irrefreada de satisfação na sociedade, guiada pela economia burguesa, está diretamente ligada à perda do Eros na relação com os objetos. Em outra ocasião, Tillich esclarece que o Eros é uma das palavras gregas para a palavra "amor" e que ela significa a busca por um todo a partir de formas culturais específicas. O Eros “está presente naqueles cientistas cujo trabalho aspira pelo todo da realidade física e, através dele, aspira também pelo último. O Eros também está presente nas artes e na literatura na medida em que eles apontam para o bom, o 
verdadeiro e o belo" (TILLICH, in: FOSTER [ed.], 1996, pp. 57-58). Essa dimensão do "todo" e, a partir do todo, do "último", é perdida na relação do ser humano moderno com o mundo de objetos que ele criou. O resultado disso é a busca de realização infinita em objetos que não apontam para além de si mesmos. Não são símbolos, mas meras coisas. Portanto, o problema não repousa simplesmente sobre a produção dos objetos da cultura moderna, nem no consumo delas, mas na forma com a qual o ser humano é levado a relacionar-se com esse mundo dos objetos. Tillich propõe ser possível outro tipo de relação do humano com o mundo.

Primeiramente, para Tillich, qualquer objeto ou evento da existência pode ser portador do sagrado, e, portanto, receber poder sacramental. Daí a importância da base sacramentológica de Tillich mostrada anteriormente para entendermos sua proposta de relação humano-mundo. Na primeira versão do texto, "Natureza e sacramento", de 1928, o autor já havia afirmado: "Em princípio, nenhum campo de objetos está descartado de uma consideração sacramental" (TILLICH, in: ALBRECHT [hg.], 1962, p. 117). Tudo na existência pode tornar-se sacramento. Mas, como vimos, na visão tillichiana, o sacramento (na forma estrita) não se torna o sagrado. Ele é somente - e não por isso desimportante, mas muito pelo contrário - portador do mesmo. A manifestação do sagrado pressupõe a natureza, o corpo, a existência. No texto de 1930, ele reafirma: "Todos os objetos e acontecimentos nos quais o ser-para-além (Seins-jenseitige) se torna presente na existência é sacramental" (TILLICH, in: HUMMEL [org.], 1992, p. 167).

\section{Conclusão}

Diante dessa situação de desintegração do mundo provocada pelas escolhas econômicas da sociedade burguesa, Tillich afirma que o cristianismo deve, sim, lutar contra sistemas totalitários, mas, também é dever do cristianismo lutar contra um sistema desintegrador, que não é construído a partir do sentido último da vida, mas sim, sobre o levantamento de forças demônicas que centralizam a regência da vida e do mundo num sistema econômico autossuficiente. Por isso, Tillich conclama os seus leitores a tomarem a responsabilidade de reconstruírem uma nova ideia de mundo no pós-guerra. Para ele, o mundo 
não poderia permanecer sobre o fundamento do capitalismo que era o verdadeiro responsável pela guerra e pela desintegração social, econômica e psicológica do mundo. Ele diz: "A desintegração social do capitalismo tardio foi a principal causa para a desintegração do mundo. A reconstrução social para além do capitalismo precisa ser o primeiro passo em direção a reintegração mundial" (TILLICH, in: PALMER [dir.], 1990, p. 164).

Como a história narra, este não foi o ocorrido. Muito pelo contrário, o pós-guerra abriu caminho para o período que ficou conhecido como "os anos dourados" do capitalismo (1945-1973) as potências capitalistas foram as que mais cresceram e se expandiram econômica e culturalmente. Entre altos e baixos do capitalismo, aqui estamos. Imersos nos méritos e prejuízos de tal sistema. Por isso, penso que as leituras contextuais de Tillich e sua afirmação de um elemento sacramental fundamental no cristianismo podem configurar, respectivamente, importante crítica e contribuição construtiva da teologia ao mundo atual.

\section{Referências}

HIGUET, E. As relações entre religião e cultura no pensamento de Paul Tillich. Correlatio 14 (2008), p. 123-143.

HOBSBAWM, E. Era dos extremos: o breve século XX: 1914-1991. São Paulo: Companhia das Letras, 1991.

MUELLER, E. "Princípio protestante e substância católica": subsídios para a compreensão de uma importante fórmula de Paul Tillich. Correlatio 10 (2006), pp. 5-18.

TILLICH, P. Autobiographical reflections. In: KEGLEY, C.; BRETALL, R. (ed.). The theology of Paul Tillich. New York: The McMillan Company, 1964, pp. 3-21.

TILLICH, P. Die religiöse Lage der Gegenwart. In: SCHARLEMANN, R. (dir.). Main works/Hauptwerke. Volume 5 /Band 5. Berlin; New York: De Gruyter; Frankfurt am Main: Evangelisches Verlagswerk GmbH, 1988, pp. 27-97.

5 Cf. HOBSBAWM, E. Era dos extremos: o breve século XX: 1914-1991. São Paulo: Companhia das Letras, 1991. Sobre "os anos dourados": pp. 253-281. 
TILLICH, P. Natur und Sakrament. In: ALBRECHT, R (hgs.). Gesammelte Werke. Band VII. Stuttgart, Evangelisches Verlagswerk, 1962, pp. 105-123.

TILLICH, P. Natur und Sakrament. In: HUMMEL, G. (org.) Main works/ Hauptwerke. Volume 6 /Band 6. Berlin: De Gruyter; New York: Evangelisches Verlagswerk GmbH, 1992, pp. 151-171.

TILLICH, P. Neue Formen christlicher Verwirklichung. Eine Betrachtung über Sinn und Grenzen evangelischer Katholizität. In: ALBRECHT, R (hg.). Gesammelte Werke. Band XIII. Stuttgart, Evangelisches Verlagswerk, 1972, pp. 92-95.

TILLICH, P. Our disintegrating World. In: PALMER, M. (Dir.). Main works/ Hauptwerke. Volume 2 /Band 2. Berlin: De Gruyter; New York: Evangelisches Verlagswerk GmbH, 1990, pp. 157-164.

TILLICH, P. Teologia Sistemática. São Leopoldo: Sinodal, 2014.

TILLICH, P. The permanent significance of the Catholic Church for Protestantism. In: HUMMEL, G. (org.) Main works/Hauptwerke. Volume 6 / Band 6. Berlin: De Gruyter; New York: Evangelisches Verlagswerk GmbH, 1992, pp. 236-242.

TILLICH, P. The revolt against the modern mind: The relevance of the Christian Message in spite of its irrelevance. In: FOSTER, D. [ed.]. The irrelevance and relevance of the Christian Message. Cleveland: The Pilgrim Press, 1996, pp. 43-63.

Submetido em: 6-1-2022

Aceito em: 18-1-2022 